\title{
Correlation Between Academic and Clinical Practice Performance of Nursing Students at a Pediatrics and Child Health Nursing Course; Mizan-Tepi University, Ethiopia
}

This article was published in the following Dove Press journal:

Advances in Medical Education and Practice

\section{Lalisa Chewaka Gamtessa iD \\ Department of Nursing, College of Health Sciences, Mizan-Tepi University, Mizan-Aman, Ethiopia}

Background: Members of the nursing profession face problems in relating knowledge with practice. However, there was no study on the correlation between academic and practice performance of pediatrics nursing in Ethiopia.

Methods: A cross-sectional study was conducted at Mizan-Tepi University using 396 nursing students' academic and practice achievements on a pediatric nursing course. SPSS version 21.0 was used for analysis. Spearman's rho correlation $\left(r_{s}\right)$, one way ANOVA, independent $t$-test and determination coefficient $\left(\mathrm{R}^{2}\right)$ were computed at $\mathrm{p}<0.05$.

Results: The academic performance was strongly correlated with practice performance of the $2015\left(r_{s}(394)=0.7, \mathrm{p}<0.001\right)$ and $2017\left(r_{s}(394)=0.7, \mathrm{p}<0.001\right)$ batches of regular students. However, there was a moderate correlation between academic and practice performance for the batch of 2016 regular students $\left(\mathrm{r}_{\mathrm{s}}(394)=0.43, \mathrm{p}<0.001\right)$. There was a moderate correlation between academic and practice performance of the $2015\left(r_{s}\right.$ $(394)=0.6)$ and $2016\left(r_{s}(394)=0.51, \mathrm{p}<0.001\right)$ batches of summer students. Linear regression analysis showed that academic performance explained $17.9 \%$ to $44.1 \%$ of variability in practice performance of the regular students. The linear regression analysis also showed that academic performance explained $26.5 \%$ to $41.2 \%$ of the variability in the practice performance of summer students. Independent $T$-test revealed significant mean performance difference by admission type (academic $(\mathrm{t}(144.7)=6.43, \mathrm{p}<0.001)$ and practice $(\mathrm{t}(115.5)=5.71, \mathrm{p}<0.001))$. The mean performance difference significantly varied with sex both at academic $(\mathrm{t}(394)=3.38, \mathrm{p}=0.001)$ and practice $(\mathrm{t}(394)=4.57$, $\mathrm{p}<0.001$ ) levels.

Conclusion: There was a moderate to strong correlation between academic and practice performance. In addition to academic performance, variation in practice was also explained by other factors which deserve more study. Enhancing academic performance can further increase practice performance. In general, the achievements of regular and male students at pediatrics was statistically significantly higher than their counterparts. Hence, female and summer nursing students deserve extra support from nurse educators to enhance their performance.

Keywords: academic, clinical practice, nursing, Mizan-Tepi, Ethiopia

\section{Introduction}

Nursing is both Art and Science. ${ }^{1,2}$ Nursing is caring for a person in a variety of health-related situations to prevent illness and promoting higher standards of
Correspondence: Lalisa Chewaka Health Sciences, Mizan-Tepi University, Mizan-Aman, Ethiopia

Tel +25I 929334l73

Email lalisachewaka@gmail.com
Advances in Medical Education and Practice 2021:12 155-162

submit your manuscrip DovePress if in $>$ http://doi.org/10.2147/AMEPS294650 
health. ${ }^{3}$ The nursing profession has its foundation on theory, practice, and research. ${ }^{4}$ Professional nurses recognize the importance of using the best knowledge to guide nursing practice. ${ }^{5}$ However, members of the nursing profession face difficulties in applying theoretical knowledge in to practice. ${ }^{6}$ This influences the members of the nursing profession's related motivation, credibility, dignity, and perceptions about nurses. ${ }^{3}$

Even though the theoretical knowledge directly influences the gap between theoretical knowledge and practice, the academic grade does not always reflect the competence of students in a clinical practice. ${ }^{7,8}$ The students' academic achievements can also vary due to different factors. ${ }^{9}$ For instance, several study's findings showed differences about the association between gender and academic achievements of students. ${ }^{10-12}$ Likewise, different study's findings also revealed that the mode of admissions affect the students' academic achievements. ${ }^{13,14}$ For this reason, nurse lecturers need to consider and relate theory with practice. ${ }^{15}$

Nursing students learn theories and understand the importance of theories and applications of these theories into practice. ${ }^{16}$ The theoretical knowledge delivered in the classroom is necessary for the clinical performance of nursing students. ${ }^{8,17}$ Clinical performance needs a clinical environment to test real-life situations by applying learned theories into practice. ${ }^{18}$ Consequently, it is compulsory to select the best environment for teaching required skills. ${ }^{17}$

One component of a BSc (Bachelor of Science) nursing graduate profile is to enable students to acquire knowledge, skill, attitude, and values in areas of pediatrics and child health nursing. ${ }^{19}$ In spite of nursing academic institutions' efforts to link theory with practice, nursing students experience shortcomings in linking theory with practice. ${ }^{17,20}$ Identifying and closing the gap for nursing students prepares them for their future career. However, this could be practical only if there is evidence on the relationship between theoretical knowledge and level of practice. Despite this, to the investigator's knowledge, there was no study conducted on the correlation of academic and clinical performance of nursing students in Ethiopia. Therefore, the objectives of this study were to describe; level of academic and clinical performance, trends in students' performance, and to determine the correlation between academic and clinical practice performance of nursing students at a course of child health and pediatric nursing at Mizan-Tepi University (MTU). The findings of the present study can be an input for nurse educators to bridge students' theoretical knowledge with practice, it can be a baseline data for interested researchers on the topic, and can be an input for a systematic review to challenge policy.

\section{Materials and Methods}

\section{Study Design, Setting and Period}

A retrospective cross-sectional study design was conducted using the performance of MTU nursing students at a course of pediatrics and child health nursing. MTU, Health Science College is found in the South Nations, Nationalities and People's Region (SNNPR), 585 $\mathrm{km}$ away from Addis Ababa. Data were collected from 2-16 September 2020.

\section{Source and Study Population}

Three recent batches of 2015, 2016, and 2017 regular nursing students and two batches of 2015 and 2016 summer nursing students were the source population. Those students who fulfilled inclusion criteria were the study population.

\section{Inclusion and Exclusion Criteria}

All students with a paired performance (academic and practice results) were included. Students who had only academic results, dropped from their batch, or were added to another batch were excluded.

\section{Study Variables Dependent and Independent Variables}

Student performance (paired academic/theoretical and practice/clinical performances at paediatrics and child health nursing) was the outcome variable. Batches, admission type, and the sex of students were explanatory variables.

\section{Data Source and Measurement of Variables}

Data were accessed with permission obtained from the MTU College of Health Science and department of nursing. The obtained data were carbon copies of official grade points of the academic and practice performance of nursing students on the paediatrics nursing course kept at the nursing department. The academic or theoretical grades were the official grade points that students achieved at pediatrics nursing theory out of $100 \%$. In the same way, the pediatrics nursing practice performances were the 
official grade points students achieved at pediatrics nursing practice out of $100 \%$. Students' performance both at academic and practice scored out of $100 \%$ were treated as continuous variables. Batch (2015-2017), admission type (regular and summer), and sex (male and female) of students were treated as categorical variables.

\section{Sample Size Determination}

All the recent three batches of 2015-2017 regular nursing students and two batches of 2015 and 2016 summer nursing students who fulfilled the inclusion criteria were included. Accordingly, the study employed a total of 396, including 325 regular nursing students and 71 summer nursing students.

\section{Sampling Procedure}

A survey of all the recent three batches of the 2015-2017 regular nursing students and the two batches of 2015 and 2016 summer nursing students were purposefully selected because these batches were all taught and evaluated by instructors with a specialty in the field (pediatrics and child health nursing)

\section{Data Collection Tool}

Data were collected using a data extraction checklist presented as Supplementary file.

\section{Data Collectors and Data Collection Procedure}

Data were collected by two academic staff of the nursing department after they were trained for one day about the data extraction procedures.

\section{Data Processing and Analysis}

The collected data were entered into Epi Info version 7 and imported into SPSS version 21.0 for cleaning and analysis. Analysis was conducted checking for all necessary assumptions. Descriptive statistics (frequency, mean, and standard deviation) were calculated for students' performance based on sex, batches, and mode of admission. Welch's $t$-test was calculated to compare students' performance according to their mode of admission. One Way ANOVA with Welch's test were used to compare students' performances for the year of entries. Spearman's rho correlation $\left(\mathrm{r}_{\mathrm{s}}\right)$ was computed to identify the association between the theoretical and clinical practice performance of students. Linear regression was used to derive
Table I Characteristics of Nursing Students at a Pediatrics and Child Health Course MTU SNNPR, Ethiopia

\begin{tabular}{|l|l|l|l|l|}
\hline \multirow{2}{*}{ Batches } & Mode of & \multirow{2}{*}{ N (\%) } & \multicolumn{2}{l|}{ Sex } \\
\cline { 4 - 5 } & & & & \multicolumn{2}{l|}{ Frequency (\%) } \\
\hline 2015 & Regular & $76(19.19)$ & $\begin{array}{l}\text { Male } \\
\text { Female }\end{array}$ & $\begin{array}{l}57(75.0) \\
19(25.0)\end{array}$ \\
\hline & Summer & $28(7.07)$ & $\begin{array}{l}\text { Male } \\
\text { Female }\end{array}$ & $\begin{array}{l}23(82.1) \\
5(17.9)\end{array}$ \\
\hline 2016 & Regular & $169(42.68)$ & $\begin{array}{l}\text { Male } \\
\text { Female }\end{array}$ & $\begin{array}{l}100(59.2) \\
69(40.8)\end{array}$ \\
\hline & & $43(10.86)$ & $\begin{array}{l}\text { Male } \\
\text { Female }\end{array}$ & $\begin{array}{l}29(67.4) \\
14(32.6)\end{array}$ \\
\hline 2017 & Regular & $80(20.20)$ & $\begin{array}{l}\text { Male } \\
\text { Fummer }\end{array}$ & $\begin{array}{l}52(65.0) \\
28(35.0)\end{array}$ \\
\hline Total & & $396(100)$ & & 100 \\
\hline
\end{tabular}

prediction equations and to obtain a coefficient of regression to identify the percentage of variation in practice performance explained by theory. The statistical significance was determined at $p<0.05$.

\section{Results}

\section{Characteristics of Study Participants}

The study was conducted on the performance (paired theory and practice results) of 396 students at the Pediatrics and Child health nursing course. Likewise, the performance of the recent three regular batches of 2015, 2016, and 2017 and two batches of 2015 and 2016 summer nursing students were analyzed. Accordingly, there were a total of 325 regular students and 71 summer students. The admission of regular students was high in 2016 and this accounted for $169(42.68 \%)$. There were only 28 (7.07\%) summer students admitted during 2015. In general, male students were dominant in all batches included in this study (Table 1).

\section{Performance of Students and Comparisons According to Batch, Admission Type and Sex of Students}

In all batches of regular and summer nursing students, males performed better than females. Concerning the admission type, the achievement of regular students was better than summer students. Regarding a particular year of entry, the performance of regular students of the batch 2017 was better than any other batches included in the current study (Table 2). 
Table 2 Performance of Nursing Students of MTU at Pediatric and Child Health Course SNNPR, Ethiopia

\begin{tabular}{|c|c|c|c|c|c|}
\hline \multirow{3}{*}{$\begin{array}{l}\text { Admission Type } \\
\text { Regular }\end{array}$} & \multirow{4}{*}{$\begin{array}{c}\text { Batches } \\
2015\end{array}$} & \multirow{2}{*}{\multicolumn{2}{|c|}{$\frac{\text { Sex }}{(\mathrm{N}) \text { Frequency (\%) }}$}} & \multicolumn{2}{|c|}{ Mean Performance (Standard Deviation) } \\
\hline & & & & \multirow{3}{*}{$\begin{array}{c}\text { Theory } \\
62.33(9.54) \\
59.11(10.97)\end{array}$} & \multirow{3}{*}{$\begin{array}{c}\text { Practice } \\
79.24(5.42) \\
76.34(6.10)\end{array}$} \\
\hline & & Male & $57(75.0)$ & & \\
\hline & & Female & $19(25.0)$ & & \\
\hline & 2016 & Male & $100(59.2)$ & $71.46(12.60)$ & $79.74(5.96)$ \\
\hline & & Female & $69(40.8)$ & $64.28(12.10)$ & $77.76(6.56)$ \\
\hline & 2017 & Male & $52(65.0)$ & $77.28(8.80)$ & $82.09(5.20)$ \\
\hline & & Female & $28(35.0)$ & $67.64(4.93)$ & $79.30(5.89)$ \\
\hline \multirow[t]{4}{*}{ Summer } & 2015 & Male & $23(82.1)$ & $59.26(8.60)$ & $75.83(5.59)$ \\
\hline & & Female & $5(17.9)$ & $56.4(4.93)$ & $75.2(5.89)$ \\
\hline & 2016 & Male & $29(67.4)$ & $64.46(7.95)$ & $76.45(5.18)$ \\
\hline & & Female & |432.6) & $55.16(6.52)$ & $75.5(3.29)$ \\
\hline
\end{tabular}

The $t$-test result showed that there was statistically a significant mean performance difference according to admission type $($ academic $(\mathrm{MD}=7.84(\mathrm{t}(144.7)=6.43, p<0.001))$ and practice $(\mathrm{MD}=4.0(\mathrm{t}(115.5)=5.71, p<0.001))$. Similarly, there was a significant mean performance difference with sex both at academic $(\mathrm{MD}=2.15,(\mathrm{t}(394)=3.38, p=0.001))$, and practice $(\mathrm{MD}=5.76,(\mathrm{t}(394)=4.57, p<0.001))($ Table 3$)$.

The one way ANOVA with post hoc test and GamesHowell correction showed a significant mean performance difference in theory among all batches of regular nursing students on the Pediatrics and Child health nursing course with $p<0.001$. Similarly, there was a significant mean performance difference between 2015 and 2017 batches at practice, $p<0.001$. However, there was a non-significant mean performance difference between 2015 and 2016 batches at practice $p=0.833$ (Table 4).
For all batches, the trends in theoretical achievement of regular and summer students at the Pediatric and Child health nursing course showed a noticeable increment. However, their practice performance remained nearly the same (Figure 1).

\section{Correlation Between Academic and Clinical Practice Performance}

The Spearman's rho test result showed a significant and strong positive relationship between academic and practice performance for $2015\left(r_{s}(394)=0.7, p<0.001\right)$, and $2017\left(r_{s}(394)=0.7, p<0.001\right)$ batches of regular students. However, there was a moderate correlation between academic and practice performance of the 2016 batch of regular students $\left(r_{s}(394)=0.43\right.$,

Table 3 Comparison of Students' Performance at Pediatrics and Child Health Nursing Course Based on Sex of Students and Mode of Admission at MTU SNNPR, Ethiopia

\begin{tabular}{|c|c|c|c|c|c|c|c|}
\hline & \multicolumn{2}{|c|}{ Levine's Test } & \multicolumn{5}{|c|}{$t$-Test for Equality of Means } \\
\hline & \multirow[t]{2}{*}{ Sig. } & \multirow[t]{2}{*}{$\mathbf{t}$} & \multirow[t]{2}{*}{ df } & \multirow{2}{*}{$\begin{array}{c}\text { Sig } \\
\text { (2-Tailed) }\end{array}$} & \multirow[t]{2}{*}{ MD } & \multicolumn{2}{|c|}{$95 \% \mathrm{Cl}$} \\
\hline & & & & & & Lower & Upper \\
\hline \multicolumn{8}{|c|}{ I. Admission type } \\
\hline Theory & 0.000 & 6.43 & 144.7 & 0.000 & 7.84 & 5.43 & 10.25 \\
\hline Practice & 0.016 & 5.71 & 115.5 & 0.000 & 4.00 & 2.60 & 5.38 \\
\hline \multicolumn{8}{|l|}{ 2. Sex } \\
\hline Theory & 0.40 & 3.38 & 394 & 0.001 & 2.15 & 1.00 & 3.40 \\
\hline Practice & 0.50 & 4.57 & 394 & 0.000 & 5.76 & 3.28 & 8.43 \\
\hline
\end{tabular}

Abbreviations: df, degree of freedom; MD, mean difference; $\mathrm{Cl}$, confidence interval. 
Table 4 Post Hoc Tests-Multiple Comparisons of Students' Performance Among Different Batches of Regular Students at Pediatrics and Child Health Nursing Course, MTU SNNPR, Ethiopia

\begin{tabular}{|c|c|c|c|c|c|c|c|}
\hline \multirow{2}{*}{$\begin{array}{l}\text { Dependent } \\
\text { Variable }\end{array}$} & \multirow[t]{2}{*}{ (I) Batch } & \multirow[t]{2}{*}{ (J) Batch } & \multirow[t]{2}{*}{ Mean Difference (I-J) } & \multirow{2}{*}{$\begin{array}{l}\text { Std. } \\
\text { Error }\end{array}$} & \multirow[t]{2}{*}{ Sig. } & \multicolumn{2}{|c|}{$95 \% \mathrm{Cl}$} \\
\hline & & & & & & $\begin{array}{l}\text { Lower } \\
\text { Bound }\end{array}$ & $\begin{array}{l}\text { Upper } \\
\text { Bound }\end{array}$ \\
\hline \multirow[t]{6}{*}{ Theory } & \multirow[t]{2}{*}{2015} & 2016 & $-6.31 *$ & 1.27 & 0.000 & -9.29 & -3.33 \\
\hline & & 2017 & $-13.13^{*}$ & 1.51 & 0.000 & $-|6.7|$ & -9.54 \\
\hline & \multirow[t]{2}{*}{2016} & 2015 & $6.31 *$ & 1.27 & 0.000 & 3.33 & 9.29 \\
\hline & & 2017 & $-6.82^{*}$ & 1.47 & 0.000 & -10.29 & -3.35 \\
\hline & \multirow[t]{2}{*}{2017} & 2015 & $13.13^{*}$ & 1.51 & 0.000 & 9.54 & $16.7 \mid$ \\
\hline & & 2016 & $6.82 *$ & 1.47 & 0.000 & 3.35 & 10.29 \\
\hline \multirow[t]{6}{*}{ Practice } & \multirow{2}{*}{2015} & 2016 & -.41 & 0.71 & 0.833 & -2.08 & 1.26 \\
\hline & & 2017 & $-3.35^{*}$ & 0.84 & 0.000 & -5.33 & -1.38 \\
\hline & \multirow[t]{2}{*}{2016} & 2015 & 0.41 & 0.71 & 0.833 & -1.26 & 2.08 \\
\hline & & 2017 & $-2.95^{*}$ & 0.75 & 0.000 & -4.72 & -1.17 \\
\hline & \multirow[t]{2}{*}{2017} & 2015 & $3.35^{*}$ & 0.84 & 0.000 & 1.38 & 5.33 \\
\hline & & 2016 & $2.95^{*}$ & 0.75 & 0.000 & 1.17 & 4.72 \\
\hline
\end{tabular}

Note: *Significant at $p<0.05$.

$p<0.001)$. Similarly, there was a significant moderate positive relationship between academic and practice performance for both batches of $2015\left(r_{s}\right.$ (394) $=0.61$, $p<0.001)$, and $2016\left(r_{s}(394)=0.51, p<0.001\right)$ summer nursing students (Table 5).

The result of linear regression analysis showed that academic performance explained $17.9 \%$ to $44.1 \%$ of the variability in the practice performance. For summer students, the result of linear regression analysis result also revealed that the academic performance explained $26.5 \%$ to $41.2 \%$ of the variability in the practice performance. The corresponding prediction equation model was also derived (Table 6).

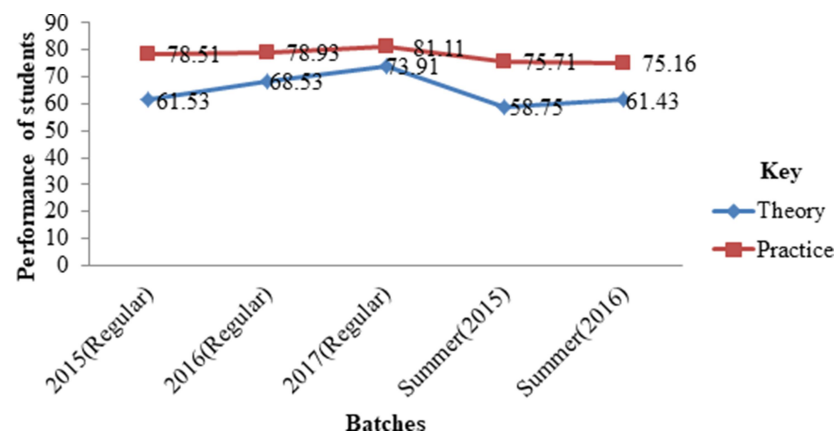

Figure I Trends in regular and summer nursing students' performance at pediatrics and child health nursing course at MTU SNNPR, Ethiopia.
Table 5 Spearman's Rho Correlation Between Theory and Practice Results of Students at Pediatrics and Child Health Nursing Course at MTU, SNNPR

\begin{tabular}{|l|c|c|c|c|}
\hline $\begin{array}{l}\text { Admission } \\
\text { Type }\end{array}$ & Batches & $\mathbf{R}_{\mathbf{s}}$ & $\begin{array}{c}\text { Sig. } \\
\text { (2 Tailed) }\end{array}$ & Interpretation \\
\hline Regular & 2015 & 0.7 & $P<0.001$ & $\begin{array}{c}\text { Strong } \\
\text { Moderate } \\
\end{array}$ \\
2016 & 0.4 & $P<0.001$ & Strong \\
\hline Summer & 2017 & 0.7 & $P<0.001$ & Moderate \\
& 2015 & 0.6 & $P<0.001$ & Moderate \\
\hline
\end{tabular}

Abbreviation: $R_{s}$, Spearman correlation coefficient.

\section{Discussion}

To the author's knowledge, this was the first study on the correlation between the academic and pediatric practice performance of nursing students in Ethiopia.

The study revealed a moderate to strong positive correlation between theory and clinical performance of nursing students on the Pediatric and Child health nursing course. The finding of this study was consistent with evidence from a Philippine Nursing University and Des Moines University. ${ }^{17,21}$ This indicated that increasing academic performance increases the clinical performance of nursing students. This may also indicate that the more active students are, academically, the better performers 
Table 6 Linear Regression Analysis Results of Students' Performance at Pediatrics and Child Health Nursing Course at MTU SNNPR, Ethiopia

\begin{tabular}{|l|l|l|l|l|l|l|l|l|}
\hline Admission Type & Batch & B & $\mathbf{X}$ & Sig. & \multicolumn{2}{l|}{ Confidence Interval } & $\mathbf{R}^{2}$ (\%) & Prediction Equation \\
\hline Regular & 2015 & $55.1 I$ & 0.38 & $\mathrm{P}<0.00 \mathrm{I}$ & 48.93 & 61.30 & 44.1 & $Y=55.11+0.38 X$ \\
& 2016 & 64.78 & 0.21 & $\mathrm{P}<0.00 \mathrm{I}$ & 60.08 & 69.50 & 17.9 & $Y=64.78+0.21 X$ \\
& 2017 & 56.54 & 0.33 & $\mathrm{P}<0.00 \mathrm{I}$ & 49.88 & 63.2 & 41.4 & $Y=56.54+0.33 X$ \\
\hline \multirow{2}{*}{ Summer } & 2015 & 49.83 & 0.44 & $\mathrm{P}<0.00 \mathrm{I}$ & 37.27 & 62.40 & 41.2 & $Y=49.83+0.44 X$ \\
& 2016 & 56.96 & 0.30 & $\mathrm{P}<0.00 \mathrm{I}$ & $47.3 \mathrm{I}$ & 66.61 & 26.5 & $Y=56.96+0.3 X$ \\
\hline
\end{tabular}

Abbreviations: $B$,constant; $Y$, practice result; $X$, theory result, $R^{2}$, R-square.

they might be in a clinical setup. Consequently providing tutorials for low achievers, using different active learning techniques such as simulation, case studies, and role-play might increase students' academic performance and therefore might also enhance their performance at clinical practice.

According to the linear regression analysis, the theoretical performance explained $17.9 \%$ to $44.1 \%$ of the variability in the practice performance of regular students. In the same way, for summer nursing students, the performance in the theory explained $26.5 \%$ to $41.2 \%$ of the variability in practice performance. In this study, the regression model evidenced that the theoretical results of nursing students at pediatrics better explained practice performance (explained variability of $17.9 \%$ to $44.1 \%$ ) when compared with studies conducted on nursing, medical and radiology students (explained variability of $16 \%$ to $20 \%) .{ }^{17,21,22}$ This may indicate that students' performance at pediatrics theory plays a better role in determining pediatrics clinical practice performance. However, variation accounted for $55.9 \%$ to $82.1 \%$ in the practice performance being due to other factors. Though this deserves further studies, students' socio-demographic characteristics, economic status, and communication between students and instructors might contribute to linking theory with practice. Proper orientation to the clinical environment and strict guideline-based assessment might positively influence students' clinical practice performance.

$T$-test result showed a significant performance difference based on sex both at theory $(\mathrm{MD}=2.15)$ and practice $(M D=5.76)$. The finding of this study was consistent with different studies. ${ }^{12,23-27}$ This difference may suggest that factors determining students' pre-university level academic performance may also affect academic performance at university level though it needs further studies. This implies that nurse educators need to provide additional support for female nursing students both in the academic and clinical setting. There was a significant performance difference according to the mode of admission both at theory $(\mathrm{MD}=7.84)$ and practice $(\mathrm{MD}=4.0)$. This might be due to difference in curricular approaches, differences in admission criteria, and social and personal characteristics. However, this again leaves a message to nurse educators that the summer nursing students deserve special consideration and treatment to support them at both theoretical and clinical setup. This may also suggest a revision of admission criteria for summer students. Nevertheless, the factors behind this difference in achievement invites other study too.

A recent trend in academic performance of nursing students showed a significant improvement. This finding was inconsistent with a study conducted on academic performance in higher learning institutions in Tanzania. ${ }^{11}$ This may be due to the different time of study and differences in the fields of study. The other possible reason might be widespread use of technological devices like smartphones by contemporary students' might made teaching materials easily accessible and use of internet browsers to visit for further assistance as necessary. From this point of view, the author highly encourages the use of technologies to make educational materials more accessible.

\section{Limitation}

Potential confounders like pre-university level academic performance, socio-demographic factors, and age of students were not controlled due to the nature of the data.

\section{Conclusion}

There was moderate to strong correlation between academic and practice performance. The academic performance explained $17.9 \%$ to $44.2 \%$ variation at practice performance. 
This indicated that variation in practice performance was also explained by other factors which deserve more study. Enhancing the academic performance of students can further increase practice performance. The achievement of regular and male nursing students at pediatrics, both academically and at practice, was statistically significantly higher than their counterparts. Therefore, to further enhance the performance of female and summer nursing students, both at classroom and clinical attachment, nurse educators should provide them with extra support. Due to the similarity in admission criteria, harmonized curriculum, similar specialty of nurse educators, and relative similarity in clinical environments, the findings of this study can be inferred to other similar universities in Ethiopia.

\section{Abbreviation}

BSc, Bachelor of Science; MTU, Mizan-Tepi University; SNNPR, South Nations, Nationalities and People's Region.

\section{Data Sharing Statement}

Data analyzed and used for this manuscript can be accessed on reasonable request from LC at lalisachewaka@gmail.com.

\section{Ethical Approval and Informed Consent}

The written permission letter with "Ref No MTU/CHS/ 147/13" was obtained from MTU College of Health Science, Academic and Research Directorate. Based on the letter from the College, data were accessed and obtained from the nursing department. Furthermore, this study was conducted in accordance with the Helsinki Declaration. ${ }^{28}$ However, there was no consent to participate due to the nature of the data. Furthermore, no identifiable data was included and reported for this work.

\section{Consent for Publication}

No publication consent to report.

\section{Acknowledgments}

The author is grateful to MTU, the College of Health Sciences and nursing department for their necessary support. Appreciation also goes to the data collectors without whom this work would have been impossible.

\section{Author Contributions}

The author was responsible for the conception and design, acquisition of data, or analysis and interpretation of data; in drafting the article or revising it critically for important intellectual content; agreed to submit to the current journal; gave final approval of the version to be published; and agreed to be accountable for all aspects of the work.

\section{Funding}

No funding to report for this work.

\section{Disclosure}

The author reports no conflicts of interest for this work.

\section{References}

1. Vega HV, Hayes K. Blending the art and science of nursing. Nursing. 2019;49(9):62-63. doi:10.1097/01.NURSE.0000577752.54139.4e

2. Doan W, Fick DM, Hill NL, Kitko L. The art and science of nursing. Artic J Gerontol Nurs. 2018;44(December):2-5.

3. Ajani K, Moez S. Gap between knowledge and practice in nursing. Procedia Soc Behav Sci. 2011;15(3927):3927-3931. doi:10.1016/j. sbspro.2011.04.396

4. Saleh US. Theory guided practice in nursing, editorial. $J$ Nurs Res Pr. 2018;2(1):2018.

5. Jasmine T. Art, science, or both? Keeping the care in nursing. Nurs Clin N Am. 2009;44(4):415-421. doi:10.1016/j.cnur.2009.07.003

6. Scully NJ. The theory-practice gap and skill acquisition: an issue for nursing education. Collegian. 2011;18(2):93-98. doi:10.1016/j. colegn.2010.04.002

7. Katrine I, Hatlevik R. The theory-practice relationship: reflective skills and theoretical knowledge as key factors in bridging the gap between theory and practice in initial nursing education. $J$ Adv Nurs. 2012;68(4):868-877.

8. Buhat-mendoza DG, Mendoza JNB, Tianela CT, Fabella EL. Correlation of the academic and clinical performance of libyan nursing students. J Nurs Educ. 2014;4(11):82.

9. Dube MB, Mlotshwa PR, Africa S, Dube M. Factors influencing enrolled nursing students, academic performance at a selected private nursing education institution in KwaZulu-Natal. Curationis. 2018;41(1):1-7. doi:10.4102/curationis.v41i1.1850

10. Day1o M. Gender differences in academic performance in a Large Public University in gender differences in academic performance in a Large Public University in Turkey department of economics serap Türüt-A 1k. 2015;2004.

11. Amani OK. Determinants of students ' academic performance in Higher Learning Institutions in Tanzania. J Educ Hum Dev. 2016;5 (4):78-86. doi:10.15640/jehd.v5n4a8

12. Philosophy L, Commons IS. Influence of gender difference on reading habit and academic achievement of undergraduate Medical Students in University of Ibadan, Nigeria. Libr Philos Pract. 2015.

13. Bolapeju M, Ogbodo PCM. Academic achievement and admission policy as correlate of student retention in Nigerian Federal Universities. Int J Bus Soc Sci. 2014;5(2):101-108.

14. Obwoge RO, Priscah MJ, Mohamed EA, Keraro FN, Kangethe S. Medical students ' KCSE grade and their relationship to academic performance: a case of egerton and moi. Science. 2017;5(2):34-44.

15. Barrett D. The clinical role of nurse lecturers: past, present, and future. Nurse Educ Today. 2007;27(5):367-374. doi:10.1016/j.nedt.2006.05.018

16. Wrenn J, Wrenn B. Enhancing learning by integrating theory and practice. Int J Teach Learn High Educ. 2009;21(2):258-265. 
17. Oducado RMF, Amboy MKQ, Penuela AC, Belo-delariarte RG. Correlation between theoretical classroom instruction and related learning experiences: evidence from a Philippine Nursing University. Int J Sci Technol Res. 2019;8(12):3666-3670.

18. Salah AA, Aljerjawy M, Salama A. Gap between theory and practice in the nursing education: the role of clinical setting. Emergency. 2018;24:17-18.

19. Ministry of Education. Ethiopian ministry of education harmonized modular curriculum for bachelor of science in nursing program. 2013. Available from: https://www.scribd.com/document/ 392985891/National-Harmonized-Nursing-Curr-March-2014. Accessed February 2, 2021.

20. Manuel J, Antonio F, Mar O. Assessment of nursing care and teaching: a qualitative approach. Int J Environ Res Public Health. 2019;16 (15):2774. doi:10.3390/ijerph16152774

21. Yoho RM, Tallerico V, Vardaxis V. Relationship between student academic and clinical performance in podiatric medical education at des moines. J Am Podiatr Med Assoc. 2012;102(4):314-318. doi:10.7547/1020314

22. Farajollahi A, Ghojazadeh M, Movaffagi A, Hossein Alikhah MN-B. Association of academic education and practical capabilities of radiology technologists. J Anal Res Clin Med. 2015;3(1):23-29. doi:10.15171/jarcm.2015
23. Münich D, Gneezy U, Niederle M. Gender gap in performance under competitive pressure: gender gap in performance under competitive pressure: admissions to Czech Universities. Am Econ Rev Pap Proc. 2014;101(3):514-518.

24. Yigzaw T, Ayalew F, Kim Y, et al. How well does pre-service education prepare midwives for practice: competence assessment of midwifery students at the point of graduation in Ethiopia. BMC Med Educ. 2015;15(130):2-10. doi:10.1186/s12909-015-0410-6

25. Eddy SL, Brownell SE, Wenderoth MP. Gender gaps in achievement and participation in multiple introductory biology classrooms. $C B E$ Life Sci Educ. 2014;13(3):478-492. doi:10.1187/cbe.13-10-0204

26. Alfarhan UF, Dauletova V. Revisiting the gender academic achievement gap: evidence from a unique environment. Gend Educ. 2019;31 (7):827-848.

27. Reardon SF, Fahle EM, Kalogrides D. Gender achievement gaps in U. S. School Districts. Am Educ Res J. 2019;XX(X):1-35.

28. Association WM. World Medical Association declaration of helsinki ethical principles for medical research involving human subjects. Bull World Health Organ. 2015;2013-2016. Available from: http://jama. jamanetwork.com/byaUniversityofGeorgiaUseron05/30/2015. Accessed February 2, 2021.
Advances in Medical Education and Practice

\section{Publish your work in this journal}

Advances in Medical Education and Practice is an international, peerreviewed, open access journal that aims to present and publish research on Medical Education covering medical, dental, nursing and allied health care professional education. The journal covers undergraduate education, postgraduate training and continuing medical education

\section{Dovepress}

including emerging trends and innovative models linking education, research, and health care services. The manuscript management system is completely online and includes a very quick and fair peer-review system. Visit http://www.dovepress.com/testimonials.php to read real quotes from published authors. 